\title{
Reframing the Achievement Gap: The Review and Explanation of the Inequitable Educational Practice
}

\author{
Huanshu Yuan ${ }^{1}$ \\ ${ }^{1}$ Texas A\&M University, College Station, TX, USA \\ Correspondence: Huanshu Yuan, Ph.D., Texas A\&M University, College Station, TX, USA.
}

Received: November 19, 2018

Accepted: December 9, 2018 Online Published: December 12, 2018

doi:10.5430/irhe.v3n4p67

URL: https://doi.org/10.5430/irhe.v3n4p67

\begin{abstract}
This paper examines the academic gaps within the frame of educational quality and practice, in terms of teaching beliefs, attitudes, expectations, pedagogy and interactions among students. A wide gap in the academic achievement exists in the United States, especially among ethnic minority students, which provokes the need of re-conceptualization of achievement gap and teacher preparation in a multicultural educational context. This research paper focuses on following major questions: "How can and do teaching beliefs, attitudes, expectations, and pedagogy differ depending on whether the teacher is serving minority students versus White students? What are the major contributing factors to the achievement gap within inequitable educational practice? What extends the "teaching gap" towards ethnic minority students in the United States? What could we do to improve teacher preparation aimed at narrowing the achievement gap?" The purpose of this paper is to explore the nature and history of the academic achievement gap framed by inequitable educational practices, analyze its influences on educational quality and outcomes; as well as illustrate what we can learn from previous studies to improve the current educational quality to meet the needs of minority students.
\end{abstract}

Keywords: achievement gap, culturally responsive teaching, education equity and quality

\section{Introduction}

One of the major aims of schools should be to help students to develop the knowledge, attitudes and skills needed to become thoughtful and active citizens. To achieve this goal, high levels and quality of educational practices are necessary. Effective and equitable education requires attentions from teachers, school administrators, parents and social communities to reduce and eliminate academic gaps in teaching preparation and teaching practices. Previous studies on this topic set a significant precedent for my research exploration. The awareness and pathways to develop a multifactor paradigm that can contribute to teacher preparation for equitable educational practices, as well as the deconstruction of teaching stereotypes and prejudice are central issues this paper will demonstrate. This paper will also summarize lessons from previous studies and literature review, with the aim of contributing to the sustainable and equal development of education in a multicultural society.

\subsection{A Working Definition of the "Achievement Gap"}

Traditionally, the common definition of the achievement gap is closely related to students' performance gaps, in terms of participation, involvements, performances and outcomes at schools. Mentioned by Gloria Ladson-Billings, "the achievement gap is one of the most talked-about issues in U.S. education, which refers to the disparities in standardized test scores between Black and White, Latino and White, and recent immigrant and White students" (2006, p.3). Historically, the term achievement gap was defined as "a matter of race and class", a gap in academic achievement persists between minority and disadvantaged students and their White counterparts in the United States (Ladson-Billings, 2006). Back to the root of this gap, how students are defined as minority and disadvantaged is based on their racial heritages and score-based achievements compared with their white peers. More cultural, social, economic and educational factors are usually hidden under the surface of students' racially defined and interpreted academic performances: class engagement, attainment, test-score-emphasized achievements.

Under the framework of inequitable educational practices as a central cause of achievement gaps, previous researchers in this field argue for a paradigm shift away from the theoretical framework emphasizing "achievement gap" in favor of one focused on a "teaching gap", which includes several systematic disparities or gaps: opportunity 
gap and teacher gap (which includes a teacher qualification gap, pedagogy gap and discipline gap) experienced by White students as contrasted with students of color. Milner (2012) asserts that traditional theorists and researchers overemphasize the outcome and test score-focused construction of an achievement gap. In this view, this field would be better served if the focus transfers to an opportunity gap framework when analyzing and explaining educational practices in highly diverse contexts, as it allows for increased focus on the causes of and contexts for disparities that exist in schools (Milner, 2012).

Referring to teacher gaps, lacking of well qualified yet professional teachers, racially constructed teaching beliefs, inappropriate teaching pedagogy and subtractive discipline could all contribute to the achievement gap under the umbrella of inequitable educational practice. Teacher preparation is in important ways related to the construction and practice of teaching knowledge, belief, and pedagogy. Teacher preparation is highly related to the quality of teachers, as well as the professional contexts in which teachers' quality and practice is created and improved.

In part, inequitable teaching practice may stem from previous teacher preparation, which leaves problems in teachers' qualities. Mentioned by Flores (2007), there are a large amount of teachers that are not as qualified to teach subject contents (such as math) in that they are "out of field" teachers. Moreover, professional and qualified teacher resources are also unequally distributed base on racial, cultural, class and socioeconomic characteristics of students and school districts. Murphy (2001) examines this issue as well as claims that the lack of qualified-teacher availability to low-income and minority students could expand the instructional gap in terms of teaching methods and expectations, learning and schooling context among minority students.

What's more, inappropriate and less adequate teacher preparation and education could result in passive teaching beliefs towards students of color or from low socioeconomic families. Teacher beliefs have a significant impact on students learning which could lead to a feeling of helplessness and frustration. Passive teaching beliefs will create a lower teacher expectations manifested in lower-level cognitive learning activities for students (Flores, 2007). Inadequate teacher preparation and qualifications will result in inadequate teaching practices, which contribute to students' low academic performances, attainments, and achievements.

A discipline gap is equally influential as teacher gap on the formation and increase of students' achievement gaps. Gregory (2010) presents research on how inequitable discipline practices may contribute to the achievement gap. He claims that the premise rests on research indicating that Black American students are generally subject to a disproportionate amount of discipline as compared to their White counterparts. Black students tended to be disciplined for more subjective behaviors such as disrespect.

Besides of racially divided curriculum, teaching beliefs and methods, the "subtractive" schooling and discipline not only broaden the achievement gap between minority students and White students, but also negatively influence on minority and immigrant students' self-construction of identities, native language development and the inheritance of their home cultural heritages. Subtractive schooling, Valenzuela (2005) defines it as the process of deculturalization----subtracting students' culture and language, which is consequential to their achievement and orientations toward schools. It embedded in the role of interactions and caring between teachers and students in the educational process (p.83).

Thus could result in a self negative reinforcement for minority students: Am I supposed to be in the class with my White peers? Am I intellectually incapable of achieving academic success? As Weis \& Fine (1993) point out, subtractive schooling and inappropriate teaching practices could destroy students' cultural identities and self-esteem. It may also result in students self-excluding themselves from actively engaging in learning processes.

\section{Inequitable Educational Practices as a Driving Force in the Achievement Gap}

Among various explanations for the achievement gap which include: cognitive ability, educational investments and school organization, poverty and associated factors, out-of-school learning experiences, social reproduction and institutional racism, inequitable education practices appears offer the most compelling explanations for the achievement gap. Inequitable education practice, in terms of teacher-learner interactions, teaching expectations, general beliefs of teaching and learning, and the design of performance assessments combined with actual teaching practice contributes to the pushing factors which impacts and shapes students' learning processes and outcomes.

Inequitable education practice can create and expand the academic gap between students of color and White students. Common misunderstandings of beliefs of teaching and learning set barriers for creating a study environment that empowers students from all groups to achieve educational excellence and equality. Historical misassumptions of the inferiority of ethnic minorities not only accumulate educational debt overtime, but also create the "stereotype threat"---which negatively influences on pedagogical practices of teachers (Ladson-Billings, 2006). 
Commonly seen stereotype threat can be reflected in the portrait of Asian American students as modern but silence minorities, African, Latino and Native American students as intellectually less prepared minorities compared to their White peers. Researchers such as Carol Lee, and Claude Steele have focused on this cultural mismatch that could contribute to the gap. Inequitable educational practices, resources, opportunities and curriculum and assessment designs could serve as the nature and driving force of the gap.

Categorizing students into different groups based on White privilege and racially yet culturally defined stereotypes, whether this is done consciously or subconsciously, could create obstacles to students' achievements. Teachers' stereotypes towards students could shape students' individual identities, self esteems, and academic performances.

Once realizing how important stereotypes are and how they might influence teachers' attitudes and expectations, students might waste brainpower thinking about how they confirm or not confirm those stereotypes. This could leave less mental capacity for them to accomplish tasks and assessments. Research refers to this as a mismatch between teacher's knowledge and cultural and students' knowledge and culture, in which these differences could lead to tensions between minority students and teachers, especially White teachers (Gregory et al, 2010).

Teachers' cultural and racial stereotypes label ethnic minority students as lower-achieving students, who have inadequate metacognitive processes and their learning suffers accordingly. Research works shows that teachers' theories and beliefs have strong implications for the way they practice teaching. Thus, the belief that achieving goals related to instruction of higher order thinking is beyond the abilities of low-achieving students (Zohar, Degani, \& Vaaknin, 2001). The consequences of that belief will result in the deprivation of low-achieving students' access to higher order thinking skills' training and performance, which is essential for their academic developments. This inappropriate teaching belief could also attribute to form the discipline gap among students of color and their White counterparts. The premise rests on research indicating that Black students, are generally subject to a disproportionate amount of discipline as compared to their White peers, which also results in the substantial loss of instructional time and high-order training assessments, racial suspension and differential rates of misbehavior, which all link to minority students' academic underperformance (Gregory et al, 2010).

Teachers' instruction and learning beliefs can produce a chain reaction in teaching expectation and teacher-student relationship, which all attribute to the causes of students' achievement gaps. The gap between low-and high-achieving students will grow wider bases on teachers and school officials differentiate ethnic minority students as low-achieving students from their white peers. Valenzuela's study in 2005 indicates that the tendency on the part of teachers and administrators to blame students' cultural, parents, and community has been observed in ethnographies of minority youth in urban schools. The shifting concern of causes of achievement gap from school itself to the students' cultural and personal backgrounds leads to schooling subtraction, as well as cultural and language segregation.

The systematically cultural and teaching mismatch reveals problems in caring relationships among students and teachers. Students' definition of education is the implicit notion that learning should be premised on authentic caring, while in contrast, to their teachers' expectation, Seguin youth prefer to be cared for before they care about school, especially when the curriculum is irrelevant and test driven (Valenzuela, 2005, p.92). The disconnection between students and teachers' expectations not only expands the achievement gap, but also increases emotional and moral boundaries among students of color. Teacher's adeptness at understanding and accommodating each student's particular circumstances, and teachers' reconsideration of students' needs can prevent students from failure, and somehow reduce the gap (Williams \& Wilson, 2002). Further, teacher expectations may be influenced by racial bias, which can also lead to teacher expectations that African American, Native American, Asian American and Latino students will have disciplinary problems (Gregory et al, 2010).

Teachers' knowledge and beliefs are crucial factors in shaping the effect of any educational endeavor, thus, teachers' beliefs in the context of low-achieving students are cognitively less qualified than high-achieving students might become a self-fulfilling prophecy (Zohar, Degani, \& Vaaknin, 2001, p.471). This misbelief will be developed into and mirrored in institutional racism, which is illustrated in Tatum's article Why are all the Black Kids Sitting Together in the Cafeteria? Previous "white supremacy" from teaching and learning beliefs and practice consists of cultural racism, inferiority of people of color and prejudice. Racism, which is "system of advantage based on race" (Tatum, 1997), creates racial advantage, namely white privilege, which broadens socioeconomic, class, and educational resources and achievement gaps among students of color/low-income family and white, middle/upper class students. Knowledge is presented at school aims at preparing students only to maintain their subordinate. 


\section{Implications of Addressing Inequitable Educational Practices for Reducing Achievement Gaps}

Attempts to address inequitable educational practices can take two forms: responding to teaching stereotypes and prejudice, and enhancing culturally responsive teaching to all students, especially for ethnic minority students. Facing the increasing number of students with multicultural backgrounds, teachers need to realize their responsibilities to modify teaching methods and attitudes for assisting minority students to achieve educational equity and excellence.

\subsection{Responding to Teaching Stereotypes and Prejudice Towards Minority Students}

In order to reduce teachers' stereotypes and prejudice in teaching practices, it is important for teachers to value and respect cultural and racial diversity among students. Prejudice and stereotype reduction serves as a significant role in creating educational equity. Stephan and Stephan (2004) define prejudice as negative attitudes toward social groups, which occurs when individuals are pre-judged based on their group memberships. This culturally yet socially relevant judgment also occurs in teaching practices based on teachers' views, expectations and attitudes towards students' different cultural, racial, and socioeconomic backgrounds.

In order to reduce teaching prejudice and stereotypes, having positive and tolerant attitudes towards diversity and differences can build the path to achieve educational equity and academic success for every students. Caring and understanding are equally important as the knowledge and awareness about visible or invisible institutional stereotypes. Teachers, educators, and school administrators must be willing to change current biases and stereotypes towards minority students.

Prejudice reduction serves as a significant mission in education. Previous curriculum and teaching beliefs can be viewed as the dominant Eurocentric value. Focusing on the achievement, cultures, values and perspectives of White students, teachers' attitudes and educational philosophy omit and devalue the knowledge, racial and cultural heritages of students of color. White western traditionalized schooling concepts may reinforce negative teaching beliefs and practices, which could result in lacking of caring and multiple understandings towards students of color and from low-socioeconomic families.

In order to reduce teaching prejudice, there are possible approaches to achieve this goal: Providing optimistic and active teacher-students relationships, changing teachers' expectations for students' competence and abilities, maintain appropriate expectations towards students, giving students higher-order thinking challenges but not overwhelming them, designing activities and work that can convey respect for students' potential. Embracing caring and empathy for minority students, teachers need also create a mixed set of expectations for each student, as well as assign competence to low status and minority students.

Responding to prejudice reduction, teachers and educators need to transform teaching beliefs and practices from racially and culturally defined biases to authentic and multicultural dimensions. Fostering cooperative learning and interactions among students, broadening the curriculum with culturally relevant concerns, and redesign evaluation standards and assessments towards students' learning outcomes can not only contribute to students' learning processes, but are also beneficial to foster comprehensive and caring teaching beliefs and practice. All these possible teaching practices and assessments could benefit to improve students' overall learning outcomes as well as reduce the achievement gap.

\subsection{Responding to Diversity and Teacher Preparation}

During the past few decades, there is a rapid growth of immigrants from various countries come to the United States. Increasing immigration and ethnic minority groups among the dominant White group is changing and challenging the structure of the U.S. school-age population. Concerns for promoting cross-cultural understanding, reducing prejudice, and striving for educational equality for minority students make the study of equitable educational practice important and necessary. Besides providing positive teaching attitudes and effective interactions for minority students, creating culturally responsive teaching is equally important to increase the educational excellence and equity.

Culturally responsive teaching is "using the cultural characteristics, experiences, and perspectives of ethnically diverse students as conduits for teaching them more effectively" (Gay, 2002. P.106). Culturally responsive teaching is an effective way to adjust traditional teaching beliefs and methods based on diversity of students' demographic features through following aspects: demonstrating high expectation and strong belief on students' capability do complete challenging and higher-order thinking assessments, contextualizing learning by connecting classroom teaching to students' lives as well as integrating students' cultural and personal experiences into curriculum and instruction, knowing, respecting and caring about students, promoting cooperative learning to engage all students, 
and developing a multidimensional educational system to meet requirements and needs for every student.

Culturally responsive teaching provides an effective guidance for teachers to modify their teaching methods and contents. The effective and appropriate teaching practice can create the path to educational excellence, as well as transform achievement gaps to achievement equity. Effective and culturally responsive teachers will achieve this goal through engaging students in active learning process which builds on their experiences and cultural backgrounds, using variety of teaching strategies, providing effective scaffolds to meet students' needs, considering students' cultural, racial and socioeconomic backgrounds and personal characteristics while designing curriculum and assessments, reinforcing students' competence and confidence, as well as reaching out and connecting community and family to schooling practice (Gay, 2002).

Equitable teaching practice is the combination of appropriate and culturally relevant teaching beliefs, attitudes, and the professional teacher preparation. Creating and maintaining a culturally connected and responsive teaching beliefs, concepts and caring could provide an even start to support professional and qualified teaching preparation and development. Applying culturally responsive teaching to instructional practice, curriculum design, and school reform could improve the access and attainment to qualified educational resources for minority students. Through reinforcing culturally responsive teaching and caring in curriculum and educational practice, teachers could be better prepared to face the diversity and differences of their students, as well as better support them to achieve academic successes.

\section{Critical Reflection on the Exploration of Inequitable Educational Practices}

The reason why and how academic achievement gaps are created and increased is multidimensional and complicated. Inequitable educational practices, unequal distribution of educational resources and school organization, poverty and associated issues, out-of-school learning experiences, institutional racism and social reproduction, those are all possible approaches and explanations to this national wide issue. Separated yet interconnected to each other, those intersecting explanations attach new and comprehensive perspectives into reconsidering close achievement gaps. Inside the educational system, where students' academic achievements are grounded, examined and compared with each other, a teaching force and practice is needed that could create, testify, and overcome challenges and frustrations minority students face due to their racial heritages and cultural backgrounds.

There are on-going and systematic barriers to educational excellence and equity for minority students which are caused by inequitable teaching resources and practices. The prevailing ideology of race inferiority has its historical roots in history and educational beliefs, which effects on teacher quality and attitudes for ethnic minority students. Linda Darling-Hammond identifies that hire and retain well qualified teachers is the most influential factor in the achievement of students (2004). Thus provides a question of what accounts for required characteristics for a qualified teacher? After reviewing previous scholarly works, equalization of teaching beliefs, attitudes and expectations, curriculum reform and culturally responsive teaching, and substantial investing in good teaching for all---these could contribute to the exploration of reducing inequitable teaching practices and achievement gaps.

Aiming at rising test scores, improving teacher quality, and developing deep learning for students, the research on modifying educational practice remains important and necessary. In terms of teacher preparation, this paper proposes several suggestions to improve its quality and outcomes: increase standards for teaching and licensure, increase the overall knowledge base for teachers, provide better working conditions and comprehensive training for new teachers, as well as increase federal and social supports to complete the above. Focusing on improving teaching practice to reduce achievement gaps, providing fully-prepared teachers for all students is important, but not sufficient. Considering the intersecting relationships among other explanations of achievement gaps, a multidimensional approach to bridge gaps among students will be more appreciated and effectively: provide a comprehensive set of social and educational supports to all students and their families, the need of major reform of the existing educational system of teacher preparation, as well as build a variety of pathways into an equity pedagogy and an empowering school culture and structure for all students.

\section{References}

Corbett, H. D., Wilson, B., \& Williams, B. (2002). The different meaning of "all children can succeed". In Effort and excellence in urban classrooms: Expecting-and getting-success with all students (pp.12-28). New York: Teachers College Press.

Darling-Hammond, L. (2004). What happens to a dream deferred? The continuing quest for equal educational opportunity. In J. A. Banks (Ed.), Hand book of research on multicultural education. San Francisco: Jossey-Bass. 
Flores, A. (2007). Examining Disparities in Mathematics Education: Achievement Gap or Opportunity Gap?. High School Journal, 91(1), 29-42. https://doi.org/10.1353/hsj.2007.0022

Gay, G. (2002). Preparing for Culturally Responsive Teaching. Journal of Teacher Education, 53(2), $106-116$.

Gregory, A., Skiba, R. J., \& Noguera, P. A. (2010). The Achievement Gap and the Discipline Gap: Two Sides of the Same Coin?. Educational Researcher, 39(1), 59-68. https://doi.org/10.3102/0013189X09357621

Ladson-Billings, G. (2006, October). From the achievement gap to the education debt: Understanding achievement in U.S. schools. American Educational Research Association Presidential Address. Educational Researcher, 35(7), 3-12. https://doi.org/10.3102/0013189X035007003

Milner, H. F. (2012). Beyond a test score: explaining opportunity gaps in educational practice. Journal of Black Studies, 43(6), 693-718. https://doi.org/10.1177/0021934712442539

Murphy, J. (2010). Environmental causes of achievement gaps: Out-of-school learning experiences. In The educators' handbook for understanding and closing achievement gaps (pp.135-146). Thousand Oaks, CA: Corwin Press.

O'Connor, C., Hill, L. D., \& Robinson, S. R. (2009). Who's at risk in school and what's race got to do with it? Review of Research in Education, 33, 1-34. https://doi.org/10.3102/0091732X08327991

Steele, C., \& Steel, C. (2004). A threat in the air: How stereotypes shape intellectual identity and performance. In J. A. Banks (Ed.), Hand book of research on multicultural education. San Francisco: Jossey-Bass.

Tatum, B. D. (1997). Defining Racism and Complexity of Identity. (Chapters 1, 2). In Why are all the black kids sitting together in the cafeteria?. Basic Books.

Valezuela, A. (2005). Subtractive schooling, caring relations, and social capital in the schooling of US-Mexican youth. In Weis, L., \& Fine, M. (Eds.), Beyond silenced voices: Class, race and gender in United States schools (pp.83-94). Albany: States University of New York.

Weis, L., \& Fine, M. (1993). Beyond silenced voices: Class, race, and gender in United States schools. Albany: State University of New York Press, pp.83-94.

Zohar, A., Degain, A., \& Vaaknin, E. (2001). Teachers' beliefs about low-achieving students and higher order thinking. Teaching and Teacher Education, 17, 469-485. https://doi.org/10.1016/S0742-051X(01)00007-5 